\title{
Using Bayesian methodology to explore the profile of mental health and well-being in 646 mothers of children with 13 rare genetic syndromes in relation to mothers of children with autism
}

Dawn Adams ${ }^{1,2}$, Richard P Hastings ${ }^{3}$, Clair Alston-Knox ${ }^{4}$, Rina Cianfaglione ${ }^{5}$, Kate Eden ${ }^{1}$, David Felce ${ }^{5}$, Gemma Griffith ${ }^{6}$, Jo Moss ${ }^{1}$, Chris Stinton ${ }^{1}$ and Chris Oliver ${ }^{1 *}$

\begin{abstract}
Background: It is well documented that mothers of children with intellectual disabilities or autism experience elevated stress, with mental health compromised. However, comparatively little is known about mothers of children with rare genetic syndromes. This study describes mental health and well-being in mothers of children with 13 rare genetic syndromes and contrasts the results with mothers of children with autism.

Methods: Mothers of children with 13 genetic syndromes ( $n=646$; Angelman, Cornelia de Lange, Down, Fragile-X, Phelan McDermid, Prader-Willi, Rett, Rubenstein Taybi, Smith Magenis, Soto, Tuberous Sclerosis Complex, 1 p36 deletion and 8p23 deletion syndromes) and mothers of children with autism $(n=66)$ completed measures of positive mental health, stress and depression. Using Bayesian methodology, the influence of syndrome, child ability, and mother and child age were explored in relation to each outcome. Bayesian Model Averaging was used to explore maternal depression, positive gain and positive affect, and maternal stress was tested using an ordinal probit regression model.

Results: Different child and mother factors influenced different aspects of mental well-being, and critically, the importance of these factors differed between syndromes. Maternal depression was influenced by child ability in only four syndromes, with the other syndromes reporting elevated or lower levels of maternal depression regardless of child factors. Maternal stress showed a more complex pattern of interaction with child ability, and for some groups, child age. Within positive mental health, mother and child age were more influential than child ability. Some syndromes reported comparable levels of depression (SMS, 1p36, CdLS) and stress (SMS, AS) to mothers of children with autism.

Conclusions: Bayesian methodology was used in a novel manner to explore factors that explain variability in mental health amongst mothers of children with rare genetic disorders. Significant proportions of mothers of children with specific genetic syndromes experienced levels of depression and stress similar to those reported by mothers of children with autism. Identifying such high-risk mothers allows for potential early intervention and the implementation of support structures.
\end{abstract}

Keywords: Syndrome, Mothers, Mental health, Positive mental health, Genetic syndrome

\footnotetext{
* Correspondence: c.oliver@bham.ac.uk

${ }^{1}$ Cerebra Centre for Neurodevelopmental Disorders, School of Psychology,

University of Birmingham, Birmingham B15 2TT, UK

Full list of author information is available at the end of the article
}

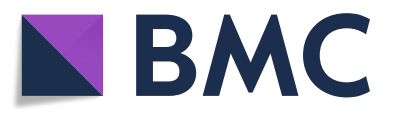

(C) The Author(s). 2018 Open Access This article is distributed under the terms of the Creative Commons Attribution 4.0 International License (http://creativecommons.org/licenses/by/4.0/), which permits unrestricted use, distribution, and reproduction in any medium, provided you give appropriate credit to the original author(s) and the source, provide a link to the Creative Commons license, and indicate if changes were made. The Creative Commons Public Domain Dedication waiver (http://creativecommons.org/publicdomain/zero/1.0/) applies to the data made available in this article, unless otherwise stated. 


\section{Background}

Mothers of children with neurodevelopmental disorders and/or intellectual and developmental disabilities (IDD) report elevated levels of stress and affective symptoms when compared to mothers of typically developing children [1-3]. These differences in maternal well-being are established by the time children are $3-5$ years of age $[3,4]$ and continue over time [5].

Given these elevated levels of stress and affective symptoms, an important question is whether there are particularly high-risk groups of mothers that might be targeted for early support and hence whether the nature of a child's neurodevelopmental disability is associated with compromised mental health. To date, the focus has been on mothers of children with autism, with consistent reports of higher levels of mental health difficulties and stress when compared to mothers of children with other neurodevelopmental disorders, including general IDD $[3,4,6]$. A meta-analysis of such studies confirms that whilst mothers of children with autism are more impacted by parenting stress, the extent to which they differ from other mothers varies considerably depending upon the comparison groups [7]. The majority of research has focused upon mothers as they tend to be the primary caregivers. The limited studies that have included or focused upon fathers draw mixed conclusions with regards to levels of stress compared to mothers and compared to fathers of typically developing children [8].

In contrast to the extensive literature focusing upon the mental health of mothers of children with autism, research into the mental health of mothers of children with known genetic aetiologies associated with neurodevelopmental disorders is comparatively sparse. Although each genetic syndrome affects only a small proportion of people, collectively the prevalence is relatively high [9]. Given that a molecular diagnosis can now be identified for most individuals with severe IDD and that the number of syndromes associated with IDD is increasing with increased genetic techniques (see [10] for a review), further research is needed to understand the pattern of aetiological group differences and factors that may be contributing to this.

Studies investigating maternal mental health in syndromes have focused predominantly on the most common genetic causes of IDD such as Fragile-X syndrome (FXS) and Down syndrome (DS), with relatively consistent results. It was concluded that mothers of children with FXS displayed fewer signs of compromised psychological well-being than mothers of children with autism, but more than mothers of children with DS [11]. Mothers of children with DS report lower levels of stress and negative impact than mothers of children with autism [12] and, in some studies, report levels of mental health problems comparable to those experienced by parents of typically developing children [13]. This raises the possibility that the so-called "Down syndrome advantage" [14] might drive the results of the few studies reporting parental stress in rarer genetic syndromes, as they typically use DS as a contrast group. The findings that parents of children with Williams or Smith-Magenis syndromes report more family problems and pessimism about their child's future than parents of children with DS [15], and that parents of children with Cornelia de Lange syndrome (CdLS) report higher levels of stress than parents of children with DS [16], must therefore be interpreted in relation to the use of DS as a contrast group. An alternative approach to comparing to DS by comparing levels of parental mental health in three rare genetic syndromes (CdLS, Cri du Chat, and Angelman syndromes [AS]) with parents of children with autism has been suggested [17], citing them as a useful benchmark high-stress comparison group. This strategy is adopted in this study.

The model of "direct" and "indirect" effects of specific syndromes and behaviour [18] can be used to hypothesise why syndrome-associated differences in maternal mental health may result. A genetic syndrome may predispose an individual to display certain behaviours or patterns of behaviour; described as the "direct" effect of the syndrome. These behaviours may evoke particular reactions from others, which is described as the "indirect" effect of the syndrome (discussed further in [19]). Syndrome characteristics may influence child presentation (the "direct" effect) which will then have differing impact upon parenting behaviours and consequences for parental well-being (the "indirect effect"). The available research in DS and FXS supports the possibility that syndromes potentially have an indirect effect on parents. However, the comparative risk for maternal mental health problems in syndromes other than these is difficult to comprehend because studies have tended to use different measures and designs and compare only one or two syndrome groups. Consequently, this limits the extent to which the available studies on the rarer syndromes can be compared with each other.

The main aim of the present study is to address the methodological limitations of existing research into the mental health of parents of children with genetic syndromes associated with neurodevelopmental disorders or disabilities. To do so, we recruited families of children with 13 different genetic syndromes and used the same measures with each group. In order to benchmark the levels of maternal well-being in these 13 syndromes and address the question of whether any of the syndrome groups in this study represent an especially high-risk group, the results were compared with those of a group of mothers of children with autism. Autism was chosen as the high-risk comparison group as multiple 
population-based studies as well as systematic reviews and meta-analyses [3, 7, 20-23] have identified parents of children with autism as being at higher risk of mental health difficulties than parents of children without autism, children with rare genetic syndromes, children with other disabilities and typically developing children. Effect sizes for this increased risk are consistently large, for example, [7]'s meta-analysis of studies focusing upon parent stress in parents of children with autism report an effect size of 1.54 for comparisons of parents of children with autism to parents of typically developing children and 0.64 for comparisons to parents of children with other disabilities. The combination of the high volume of research from across the world with the consistent finding of elevated levels of maternal mental health difficulties provides a strong rationale for using autism as a "high-risk" comparison group against which the other syndromes can be compared.

In addition to a focus on mental health problems, we are mindful of the growing research base regarding the positive impact of caring for an individual with IDD $[24,25]$. Intriguingly, a population-based study [3] found no disability group differences and no evidence of differences compared to mothers of children without disabilities for maternal positive mental health. A similar pattern of no group differences for positive impact has been found in genetic syndrome family research studies [12, 26], but the research remains limited.

Therefore, we included both negative and positive well-being measures in the present research to answer the following research questions:

1. What are the profiles of positive mental health, stress and depression in mothers of children with a range of rare genetic syndromes and how do these compare with mothers of children with autism?

2. Does genetic syndrome predict levels of maternal mental health and if so, is this more predictive than basic child variables that differ between the syndromes, such as level of ability?

\section{Methods}

\section{Participants}

For all of the syndrome groups included in the study with the exception of Rett syndrome (RTT) (AS, CdLS, DS, FXS, Phelan-McDermid [PMS], Prader-Willi [PWS], Rubinstein-Taybi [RTS], Soto, Smith-Magenis [SMS], Tuberous Sclerosis Complex [TSC], 1p36 deletion syndrome, 8p23 deletion syndrome and the autism group [ASD]), questionnaire packs were distributed to members of each syndrome support group within the UK. [27] provides detailed information on the recruitment process but briefly, questionnaire packs were provided to the syndrome support groups who then sent them out to their members. The research team only received information on demographics, child and family variables from the participants who consented and returned their questionnaire. The 87 mothers of daughters with RTT were recruited in a study which used the British Isles Rett Syndrome Survey (BIRSS) as a sampling frame (see [28] for further details).

Caregivers from 816 families responded and consented to take part. Due to small numbers and the lack of ability to examine differences across groups, thirty-nine (3.3\%) were excluded because they were not the child's mother or adoptive mother (i.e. were fathers, grandparents, foster carers or paid carers) and $11(1.2 \%)$ were excluded as the child was aged under 2 years. Respondents who completed fewer than $75 \%$ of items in the questionnaires of interest to this study were excluded to minimise the impact of missing data. As per [27], data were excluded if the participant did not have a genetic diagnosis from a clinical geneticist, pediatrician, neurologist or psychiatrist. In relation to the ASD group, participants who had scores below the cut-off of 15 on the Social Communication Questionnaire (SCQ) [29] were excluded to provide additional confidence in the reported diagnoses. To reduce the risk of potential overlap between the ASD and the syndrome groups, participants in the autism group were asked if their child had any additional diagnoses or a diagnosis of a genetic syndrome. No participants listed any genetic syndrome in addition to the autism diagnosis.

Following exclusions, a sample of 712 mothers was retained for analysis. The sample consisted of 646 mothers of children with one of 13 genetic syndromes and 66 mothers of children with ASD. Table 1 summarises the number, age and gender distribution of the children and age of the mothers. The range in sample sizes partly reflects the range in prevalence rates for the syndromes. For example, the prevalence of AS $(1: 10,000-40,000)$ [30] is considerably lower than that for FXS $(1: 5,000)$ [31]. The current article does not allow for a description of the genetic cause or phenotype of each individual syndrome but excellent descriptions are available in Table 1 of [32] and within the wider literature.

\section{Demographic characteristics}

The mean age of the 712 children was 15.2 years (sd 9.5) and the mean age of the mothers was 46.6 years (sd 9.8). Fifty-seven percent of the children were male and $96.9 \%$ were the participants' natural mothers, with the remainder being long-term adoptive mothers. Gender differences were as expected given that only males with FXS were recruited; RTT almost exclusively affects females, and ASD spectrum disorder is more prevalent in males. However, a higher proportion of males than expected was also found in the $1 \mathrm{p} 36$ syndrome group. Data from 
Table 1 Demographic characteristics (age, gender) and descriptive data by syndrome group

\begin{tabular}{|c|c|c|c|c|c|c|c|c|c|c|c|c|c|c|c|}
\hline & AS & ASD & CdLS & DS & $\mathrm{FXS}^{\mathrm{a}}$ & PMS & PWS & $\mathrm{RTT}^{\mathrm{a}}$ & RTS & SMS & Soto & TSC & $1 p 36$ & $8 p 23$ & Total \\
\hline$n$ & 28 & 66 & 44 & 29 & 102 & 31 & 101 & 87 & 47 & 20 & 38 & 71 & 26 & 22 & 712 \\
\hline $\begin{array}{l}\text { Child mean } \\
\text { age (sd, range) }\end{array}$ & $\begin{array}{l}10.9 \\
3.3 \\
(3-15)\end{array}$ & $\begin{array}{l}15.5 \\
6.5 \\
(6-42)\end{array}$ & $\begin{array}{l}12.8 \\
8.2 \\
(2-45)\end{array}$ & $\begin{array}{l}25.4 \\
11.8 \\
(8-45)\end{array}$ & $\begin{array}{l}15.0 \\
8.2 \\
(2-42)\end{array}$ & $\begin{array}{l}11.3 \\
8.4 \\
(2-37)\end{array}$ & $\begin{array}{l}12.2 \\
8.1 \\
(2-45)\end{array}$ & $\begin{array}{l}20.1 \\
10.2 \\
(4-47)\end{array}$ & $\begin{array}{l}21.3 \\
10.5 \\
(6-53)\end{array}$ & $\begin{array}{l}11.6 \\
7.2 \\
(3-32)\end{array}$ & $\begin{array}{l}15.3 \\
9.3 \\
(2-43)\end{array}$ & $\begin{array}{l}18.8 \\
10.7 \\
(2-50)\end{array}$ & $\begin{array}{l}10.9 \\
8.9 \\
(2-39)\end{array}$ & $\begin{array}{l}10.8 \\
5.5 \\
(4-21)\end{array}$ & $\begin{array}{l}15.2 \\
9.5 \\
(2-53)\end{array}$ \\
\hline$\%$ Male child & 46.4 & 86.4 & 47.7 & 53.3 & 100 & 45.2 & 52.3 & 0 & 55.3 & 60 & 68.4 & 60.6 & 78.6 & 68.2 & 57.0 \\
\hline $\begin{array}{l}\text { Maternal mean } \\
\text { age }(s d)\end{array}$ & $\begin{array}{l}40.8 \\
4.9\end{array}$ & $\begin{array}{l}47.9 \\
6.8\end{array}$ & $\begin{array}{l}45.1 \\
9.1\end{array}$ & $\begin{array}{l}59.1 \\
12.3\end{array}$ & $\begin{array}{l}45.6 \\
9.5\end{array}$ & $\begin{array}{l}42.3 \\
9.9\end{array}$ & $\begin{array}{l}44.5 \\
8.5\end{array}$ & $\begin{array}{l}50.7 \\
9.2\end{array}$ & $\begin{array}{l}49.8 \\
9.9\end{array}$ & $\begin{array}{l}43.7 \\
8.5\end{array}$ & $\begin{array}{l}46.3 \\
8.3\end{array}$ & $\begin{array}{l}48.1 \\
10.3\end{array}$ & $\begin{array}{l}41.2 \\
10.8\end{array}$ & $\begin{array}{l}39.6 \\
6.1\end{array}$ & $\begin{array}{l}46.6 \\
9.8\end{array}$ \\
\hline Speech \% verbal & 32.1 & 92.4 & 68.2 & 100 & 94.2 & 38.7 & 98 & - & 83 & 80 & 92.1 & 76.1 & 57.7 & 91.9 & 82.3 \\
\hline Hearing \% normal & 92.9 & 98.5 & 56.8 & 58.6 & 97.1 & 90.1 & 99.0 & - & 80.9 & 55 & 76.3 & 94.4 & 61.5 & 90.9 & 87.3 \\
\hline Vision \% normal & 85.7 & 86.4 & 63.6 & 43.3 & 88.3 & 71.0 & 73.3 & - & 51.1 & 75.0 & 73.7 & 88.7 & 26.9 & 45.5 & 74.4 \\
\hline obility \% mobile & 39.3 & 92.4 & 54.5 & 100 & 86.4 & 71 & 78.2 & - & 74.5 & 70 & 81.6 & 78.9 & 46.2 & 59.1 & 76.6 \\
\hline Self-help \% able/partly able & 14.3 & 89.2 & 40.9 & 90 & 88.2 & 22.6 & 78.2 & - & 80.9 & 60 & 84.2 & 66.2 & 42.3 & 59.1 & 70.4 \\
\hline
\end{tabular}

${ }^{a}$ Gender distribution can be explained in these groups as only males with FXS were recruited and RTT almost exclusively affects females

AS Angelman Syndrome, ASD Autism Spectrum Disorder, CdLS Cornelia de Lange syndrome, DS Down Syndrome, FXS Fragile-X Syndrome,

PMS Phelan McDermid Syndrome, PWS Prader-Willi syndrome, RTT Rett Syndrome, RTS Rubenstein Taybi syndrome, SMS Smith Magenis Syndrome,

TSC Tuberous Sclerosis Complex, $1 p 361 p 36$ deletion syndrome, 8p23 8p23 deletion syndrome

the Wessex questionnaire (see Measures section below) reflect the different physical and cognitive profiles associated with the different syndromes.

\section{Ethical considerations}

Ethical approval was obtained for this study in 2010 from Coventry Research Ethics Committee, as part of a larger ongoing study entitled 'Understanding behaviour and family adjustment in individuals with neurodevelopmental disorders' (REC reference number: 10/H1210/01).

All procedures performed were in accordance with the ethical standards of the institutional research committees and with the 1964 Helsinki declaration and its later amendments or comparable ethical standards.

Informed consent was obtained from individuals who had the capacity to provide consent themselves. For those who did not have capacity to provide their own consent, parents or carers were able to act as consultees. Consultees were asked to advise on what the wishes of the individual would be if they were able to consent from themselves.

\section{Measures}

A background questionnaire was used to collect demographic information and, for the ASD group, included the Social Communication Questionnaire [29]. The Wessex Scale [33] was also used to collect data on each child's mobility, self-help scores, speech, vision and hearing. Within this study, the Wessex self-help scale was used as a proxy measure of ability (as per $[34,35])$. The mothers then completed the following four questionnaires addressing dimensions of their well-being.

The Positive Gain Scale (PGS) [36] comprises seven items to assess the direct positive aspects of having a child with a disability, such as "since having this child I feel I have grown as a person". Each item is rated on a 5-point Likert scale. These scales were reverse coded for this study, so the higher the score, the more positive gains reported by the participant. Internal consistency is good, with Cronbach's Alpha being reported as .71 [17] and .93 within the current sample.

To minimise demands upon mothers, the Positive Affect Scale-5 (PAS5) was used (as per [17]). This comprises five items from the Positive Affect Scale (PANAS) [37] with the highest total item correlations. Correlation of the full 10-item Positive Affect Scale and the Positive Affect Scale- 5 as moderate to strong $(r=.60)$ has been reported [17]. Participants were presented with five descriptive words, such as "strong" and "interested" and asked to rate the extent to which they felt this way over the past week on a Likert-type scale. Cronbach's Alpha was .86 within the current sample.

The seven items assessing depression were selected from the Hospital Anxiety and Depression Scale (HADS) [38]. Although this measure was published in 1983, it continues to have good test-retest reliability and concurrent validity data reported at subscale and total score levels for parents of children with neurodevelopmental disorders [39, 40]. In the present sample, Cronbach's Alpha was strong (.89).

The Parent and Family Problems Subscale from the Questionnaire on Resources and Stress - Short Form (QRSF) [41], was used to measure general stress associated with raising a child with intellectual disabilities. The five items assessing depression were excluded to reduce potential overlap (as per [17]). This measure continues to be used and reported in recent studies of children with a range of disabilities (e.g. [42, 43]). Mothers were asked to circle "true" or "false" on seven items, such as "other members of the family have to do without things because of <name>". The Kuder-Richardson coefficient for this version of the questionnaire was .82 within the current sample. 


\section{Statistical analysis}

Bayesian methods are emerging in developmental research, and in psychological research more broadly [44]. The approach has been described and discussed in articles in a range of journals relevant to the field of intellectual disability research (e.g. [44-46]). In brief, Bayes's theorem is a model for learning from data, and consequently, the Bayesian paradigm interprets probability as the subjective experience of uncertainty [47]. As noted [46], Bayesian methods are not meant to test whether a null hypothesis should be rejected, but aim to capture the strength of the evidence for specific hypothesised beliefs. Instead of assuming that there is a fixed but unknown parameter of interest (e.g. one true mean, one true regression coefficient), the Bayesian view is that all unknown parameters should be treated as uncertain, and therefore should be described by a probability distribution [44].

Bayesian analysis formulates this probability distribution for the parameters (and functions of the parameters) using a combination of data (a likelihood distribution) and a prior distribution, which represents the researchers' knowledge prior to data collection. Although there is a wealth of literature documenting elevated stress and depression in mothers of children with ASD, there is comparatively little on mothers of children with genetic syndromes, particularly relating to positive mental health. Given this, it was decided that there was insufficient information across all the syndromes in this study to set an informative prior belief for how each syndrome may differ, so the hypothesised belief was that there is no difference on measures of mental health between the syndrome groups and ASD. The prior distribution for parameters for syndromes other than ASD was set as a normal distribution centered around zero, and the variance was set to allow variation from ASD. The ASD group was used as the base-level parameter, and a comparison and marker for elevated difficulties was modelled.

The data analysis was undertaken in three stages for each measure of maternal mental health except stress, where only the first two stages were undertaken due to the data being measured on a dichotomous scale (for which Bayesian model averages have not yet been developed). The continuous measure scale data were first analysed as a linear regression where only syndrome was considered, using a Bayesian framework. The linear regression model used in stage 1 is represented by:

$$
\begin{aligned}
& \text { Measure } \sim N\left(X \beta, \sigma^{2}\right) \\
& X \beta=\beta_{\text {Autism }}+\beta_{\text {syndrome_difference_autism }} \\
& p\left(\beta_{\text {Austism }}\right) \sim N\left(\eta_{A}, \varepsilon_{A}^{2}\right) \\
& p\left(\beta_{\text {Syndrome_difference_autism }}\right) \sim N\left(\eta_{B}, \varepsilon_{B}^{2}\right) \\
& p\left(\sigma^{2}\right) \sim \operatorname{InvGamma}(v, \omega)
\end{aligned}
$$

In this framework, the likelihood of the measure of interest (depression, positive gain and positive affect) is considered to be normally distributed, with a mean based on the regression model parameters, the explanatory data and constant variance. The unknown regression parameters $(\beta)$ have a prior distribution that is also normal, with hyperparameters for the mean and variance given in Table 2. The error variance, $\sigma^{2}$ is modelled using an inverse gamma prior distribution.

Computation was performed using Markov Chain Monte Carlo (MCMC) estimation with the MCMCregress function from the MCMCpack library [48] in R [49]. The results were then presented graphically and grouped using the estimated posterior distributions that were statistically similar. Within each figure, shadings were used to represent groupings with similar posterior estimates and credible intervals of $80 \%, 50 \%$ and $20 \%$ provided.

As a Bayesian regression model determined that Wessex score, child and maternal age varied between groups, these factors were entered into a classification and regression tree (CART) to explore their impact, if any, on the measure of maternal well-being. This CART analysis informed the final stage of the analysis by highlighting potential interactions and allowing us to estimate suitable factorisation levels, such as carer age, on continuous data. Continuous data are unlikely to change gradually as a regression model would imply, but are more likely to cluster into a category. A Bayesian model averaging (BMA) approach was used to assess the relative influence of each of these factors on maternal mental health. BMA is an extension of the Bayesian inference methods that consider both model and parameter uncertainty. Instead of selecting one particular model as "true", BMA combines weighted fitted values from multiple models to estimate the posterior distribution of the model parameters. Using this technique, a posterior mean (the value expected under the BMA), posterior standard deviation and the probability of a variable's inclusion are provided. The probability of inclusion reflects how certain the model is that the coefficient is not zero, taking into account model uncertainty and the other variables. An inclusion probability of 1 indicates $100 \%$ certainty that the factor should be included in the model, and an inclusion probability of .5

Table 2 Fixed hyperparameters for the prior distributions of linear regression coefficients $\beta_{\text {ASD }}$ and $\beta_{\text {Syndrome_difference_ASD }}$ and the variance $\left(\sigma^{2}\right)$ for the continuous measures of maternal mental health

\begin{tabular}{llll}
\hline & Depression & Positive Gain & Positive Affect \\
\hline$\eta_{\mathrm{A}}$ & 7.6 & 21.0 & 15.0 \\
$\varepsilon_{\mathrm{A}}$ & 0.5 & 2.0 & 0.5 \\
$\eta_{\mathrm{B}}$ & 0.0 & 0.0 & 0.0 \\
$\varepsilon_{\mathrm{B}}$ & 2.0 & 2.0 & 2.0 \\
$\vee$ & 0.001 & 0.001 & 0.001 \\
$\omega$ & 0.001 & 0.001 & 0.001 \\
\hline
\end{tabular}


indicates $50 \%$ certainty [50]. BMA computation was estimated using the R BAS library [51] with the default prior distributions for all parameters.

Maternal stress was measured on a scale derived from dichotomous variables, so an ordinal probit regression model was fitted using an MCMC scheme. Vague priors were employed to model the transition of individuals from one stage of stress to another in an ordered sequence. Estimation was conducted using the $\mathrm{MCMCo}-$ probit function from the MCMCpack library [48] in R [52], using the algorithm proposed by [53].

\section{Results}

The simulated posterior distributions with credible intervals for each of the four measures are displayed in the upper panels of Figs. 1, 2, 3, 4. Data are presented in ascending order across the groups, meaning that the order of syndrome groups differs between each figure. Higher scores represent higher levels of the area being assessed, that is, higher levels of positive affect and positive gain, but also higher levels of depression and stress. Groupings (represented by shadings) are based on the posterior probabilities documented in Table 3. The CART diagrams are provided in the Additional file 1, items 1 to 4 .

\section{Positive mental health \\ Positive gain}

The upper panel of Fig. 1 documents the simulated posterior distributions for positive gain with credible intervals across all syndrome groups and ASD. The CART informed the inclusion of syndrome group, child age $(\leq />8)$ and maternal age $(\leq />53)$ in the BMA. The results of the BMA (summarised graphically in the lower panel of Fig. 1) indicate two groups based upon syndrome (inclusion probability .75), with Group 1 (containing ASD, AS, CdLS, FXS, PWS, SMS, Soto, 1p36, 8p23 and TSC) reporting significantly lower positive gain than Group 2 (containing DS, RTS, PMS, RTT). Increasing child age (inclusion probability .41) and carer age (inclusion probability .36) had a mild negative influence on positive gain, with a slightly stronger impact of carer age in syndrome Group 2 than in Group 1 (inclusion probability .41).

\section{Positive affect}

The upper panel of Fig. 2 documents the simulated posterior distributions for positive affect with credible intervals across all syndrome groups and ASD. The CART informed the inclusion of syndrome group and maternal age $(</ \geq 36)$ into the BMA. The results of the BMA (summarised graphically in the lower panel of Fig. 2) indicate two groups based upon syndrome (inclusion probability .70), with Group 1 (containing ASD, CdLS, DS, FXS, PMS, PWS, RTS, SMS, Soto, 1p36, TSC) reporting significantly lower positive affect than Group 2 (containing AS, RTT, 8p23). Increasing carer age (inclusion probability .89) had a strong negative influence on positive affect, with a slightly stronger impact of carer age in syndrome Group 1 than in Group 2 (inclusion probability .37).

\section{Mental health difficulties \\ Depression}

The upper panel of Fig. 3 documents the simulated posterior distributions for depression with credible intervals across all syndrome groups and ASD. The CART informed the inclusion of syndrome group and Wessex Score $(=/<9)$ into the BMA. The results of the BMA (summarised graphically in the lower panel of Fig. 3) indicate three groups based upon syndrome (inclusion probability .84 for Group 2, 1.0 for Group 3), with Group 1 (containing ASD, CdLS, SMS, 1p36) reporting significantly higher depression than Group 2 (containing AS, FXS, PWS, TSC, PMS), both of which report higher depression than Group 3 (containing DS, Soto, RTS, RTT, 8p23). Whether the child's Wessex self-help score was at or below the maximum did not influence depression scores in Group 1 or Group 3, but had a significant influence on Group 2 (inclusion probability .77), with higher levels of depression in mothers of children who had a Wessex score below the maximum score of 9. It is important to note that depression scores in Group 1 are much higher than those for Groups 2 and 3, and as such, the Wessex score has limited ability to increase the depression rating.

As the HADS has a cut-off score for clinical levels of depression, the inclusion probability for mothers in each syndrome group being depressed was calculated and is presented in Table 3 (without consideration of child or carer variables). The syndromes in Group 1 of the BMA (ASD, CdLS, SMS, 1p36) have a $49-56 \%$ risk of scoring above the clinical cut-off, those in Group 2 (AS, FXS, PWS, TSC, PMS) a $37-41 \%$ risk, and those in Group 3 (DS, Soto, RTS, RTT, 8p23) a $29-35 \%$ risk.

\section{Maternal stress}

The upper panel of Fig. 4 documents the simulated posterior distributions for maternal stress with credible intervals across all syndrome groups and ASD. The CART identified syndrome group first, then Wessex $(=/<9)$ and finally child age $(\leq />8)$ as factors influencing maternal stress scores. The lower panel of Fig. 4 depicts simulated posterior mean scores for each syndrome only for those scoring below the maximum score of 9 on the Wessex self-help score. The data are divided by age group, with the grey line representing maternal stress levels for each syndrome when the child is age 8 , and the black line representing each syndrome when the child is age 16 . 


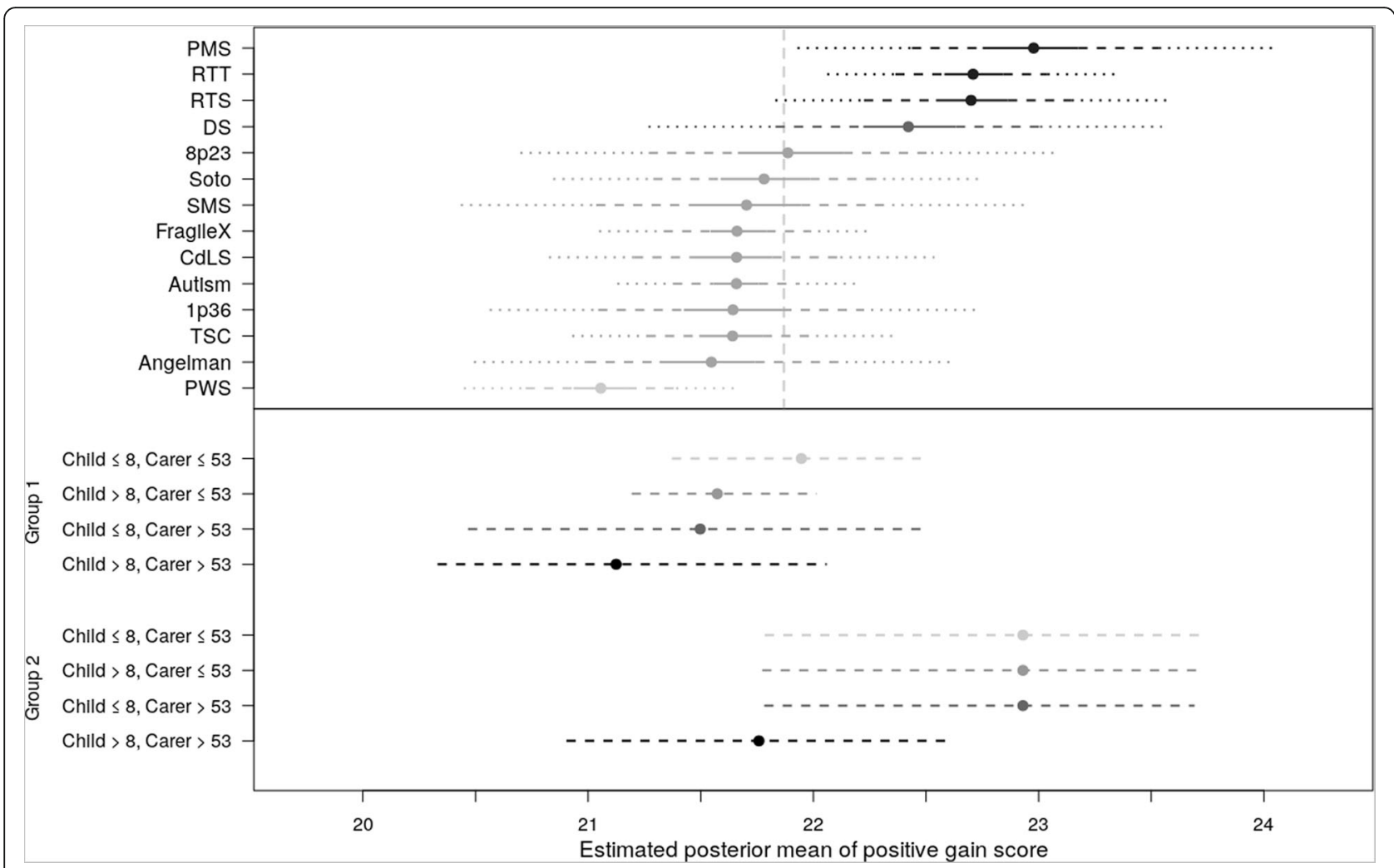

Fig. 1 Positive Gain by syndrome group (upper panel) and by BMA groupings (lower panel). Upper panel: Estimated posterior mean of Positive Gain by syndrome group. Extended lines represent Credible Intervals: solid 20\%, dashed 50\%, dotted 80\%. Vertical dashed line is mean of all participants. Lower panel: Posterior probabilities of Positive Gain based on BMA. Group 1: Autism, AS, CdLS, FXS, PWS, SMS, Soto, 1p36, 8p23, TSC. Group 2: DS, RTS, PMS, RTT

These variables were entered into the ordinal probit regression. Maternal stress tended to increase with child age (Bayesian posterior $p$-value $=.01$ ) with the exception of Soto (Bayesian posterior p-value <.01), AS (posterior $\mathrm{p}$-value $=.02$ ), and SMS (Bayesian posterior p-value $=.004)$ where it decreased with child age.

\section{Discussion}

This is the first study exploring mental health and well-being in mothers of children with 13 rare genetic syndromes associated with neurodevelopmental disorders or disabilities in relation to each other and to mothers of children with ASD. It also provides the first published description of which we are aware of stress, depression and positive mental health of mothers of children with four syndromes: RTS, Soto, $1 \mathrm{p} 36$ and $8 \mathrm{p} 23$. The use of the Bayesian approach is both novel and important, as it allows for exploration of relative influences on different child or mother factors in relation to a range of maternal mental health measures whilst modelling for the uncertainty in this underresearched area.

The first key finding is that for different aspects of mental health, including positive mental health, different child and mother factors influenced the groupings of scores, and that the importance of these factors on maternal mental health is different for different syndromes. For example, the BMA for depression notes that mothers of children with some syndromes (ASD, CdLS, SMS, 1p36) had elevated levels of depression regardless of child ability or age, or age of the mother, and others had relatively low levels of depression (DS, Soto, RTS, RTT, 8p23) regardless of these variables. However, levels of maternal depression in AS, FXS, PWS, TSC and PMS showed a syndrome by ability interaction: mothers of children with the highest ability score on the Wessex had lower depression scores than mothers of children who had a score below the maximum on the Wessex (posterior mean depression ratings 4.46 and 6.26 respectively).

For maternal stress, the relationship was more complex, with the CART decision tree and regression both highlighting an interaction between Wessex score and syndrome, but also identifying the importance of child age within those with lower than maximum on the Wessex within a specific group of syndromes. For that group, stress tended to increase with child age: however, 


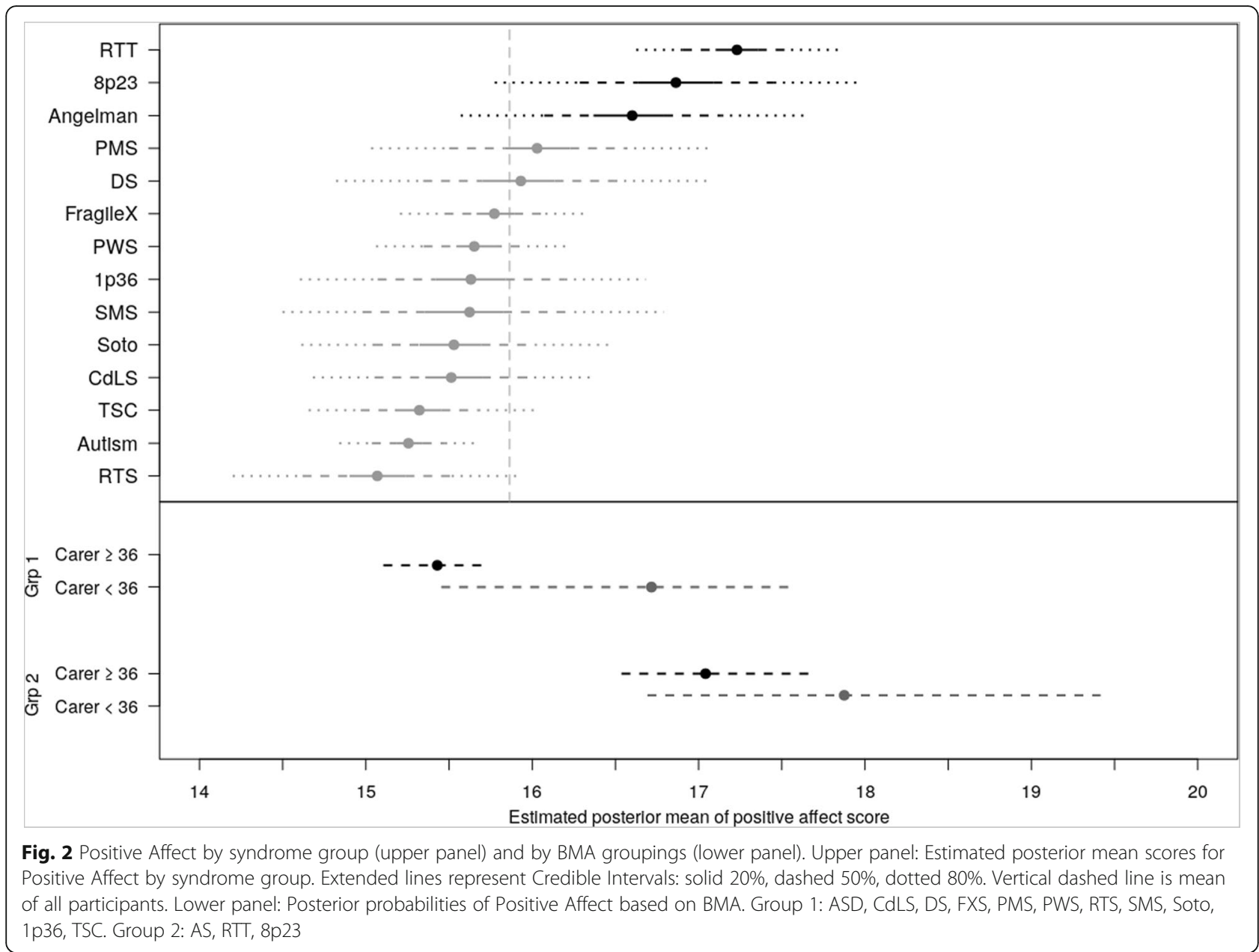

in AS, Soto and SMS, the opposite pattern was noted. Within positive mental health, carer and child age are important considerations, although the BMA again highlighted that these factors have different influences on different groups of syndromes for different aspects of positive mental health.

The second key finding is the identification of some syndromes where a notable proportion of mothers will be experiencing comparable levels of depression (SMS, 1p36, CdLS) and stress (SMS, AS) to mothers of children with ASD, a group that has always been highlighted within the literature as being at elevated risk for mental health difficulties. The prevalence rates of ASD in these syndromes vary (AS 34\%, CdLS 43\%, SMS 54\% meet cutoff on the SCQ, 1p36 "few cases" [54-56]), and are comparable with some of the syndromes explored within this paper where mothers do not report comparable levels of mental health difficulties, for example, PMS $52.5-55 \%$, Soto $83.3 \%$, and RTT 61\% [56-58]. Therefore, the similarities in mental health difficulties between these syndromes and ASD cannot be explained simply by the presence of "autism-symptoms" within these syndromes. This may suggest that different "direct effects" of a syndrome may have differing "indirect effects" in the context of the broader physical and cognitive phenotype. The finding that parents of different syndromes have elevated scores in different aspects of mental health difficulties is also of significance.

It is important to consider why maternal psychological well-being may be associated with child disability aetiology and why specific aetiologies interact differently with child and parent characteristics for certain aspects of maternal mental health. The research pertaining to parental stress in idiopathic intellectual disability and ASD has highlighted the impact of behavioural characteristics and behaviours that challenge on parental stress in both cross-sectional and longitudinal studies [59]. The presence of behaviours that challenge may be a significant factor contributing to the results reported in this study. However, the impact of behaviours that challenge on parent stress and well-being, over and above the syndrome, differs between different syndromes (e.g. [12]). It cannot 


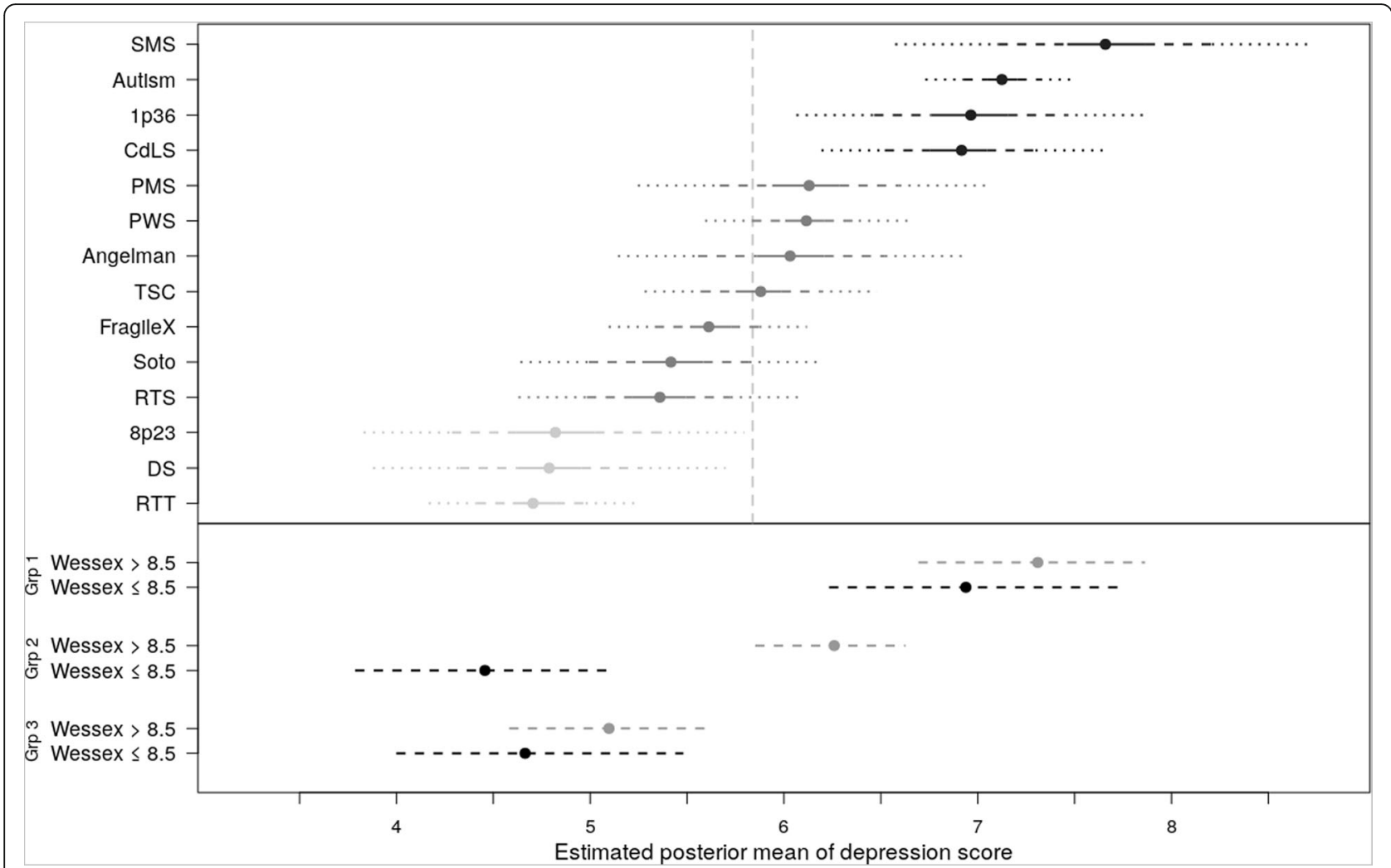

Fig. 3 Depression by syndrome group (upper panel) and by BMA groupings (lower panel). Upper panel: Estimated posterior mean scores for Depression by syndrome group. Extended lines represent Credible Intervals: solid 20\%, dashed 50\%, dotted 80\%. Vertical dashed line is mean of all participants.Lower panel: Posterior probabilities of Positive Gain based on BMA. Group 1: ASD, CdLS, SMS, 1p36, Group 2: AS, FXS, PWS, TSC, PMS, Group 3: DS, Soto, RTS, RTT, 8p23

therefore be assumed that the between-syndrome similarities and differences in parental mental health and well-being identified within this study can be solely explained by behavioural difficulties as "behaviour is but one aspect of aetiology-related characteristics that affect these children's everyday lives" [60].

In their review of the literature, [60] highlight the importance of considering the "non-behavioural" aspects that may impact upon parental well-being including the child's health status, the level of caregiving required, both parent and child personality, child facial characteristics and physical phenotype, and the timing and predictability-expectedness of problems. Parents of children with different syndromes have different concerns about their children [61] and there may be different levels of parental acceptance and understanding of the genetic cause (including aspects relating to hereditability) and societal acceptance of the genetic syndrome [11]. In qualitative interviews, mothers of young people with genetic syndromes reported that negative public reactions, difficulties with social inclusion, problems accessing social and medical services and a lack of accessible knowledge about the syndrome, were factors that increased maternal stress
[62]. It is therefore critical that future explorations of maternal well-being in mothers of children with rare genetic syndromes consider the behaviour (or behavioural phenotype) within the broader subset of phenotypes of the syndrome, including the physical (including physical presentation and physical health) and cognitive phenotypes (including autism symptomatology). Now that the current study has documented that child and mother variables influence the profile of maternal mental health across a range of genetic syndromes, researchers can begin to model and explore further sources of variance, with a focus on child behaviour in the context of other child, parent and family characteristics. Just as [63, 64] developed syndrome-specific models of syndromes to behaviour, these results of further explorations could model the "indirect" effect of syndromes [19] to consider individual and systemic factors within individual or groups of syndromes. Although this is highlighted as an important avenue for future research, it is likely that such relationships will be complex and there will inevitably be variations both within and between syndromes.

Parents, syndrome support groups and professionals encourage the use of knowledge relating to genetic 


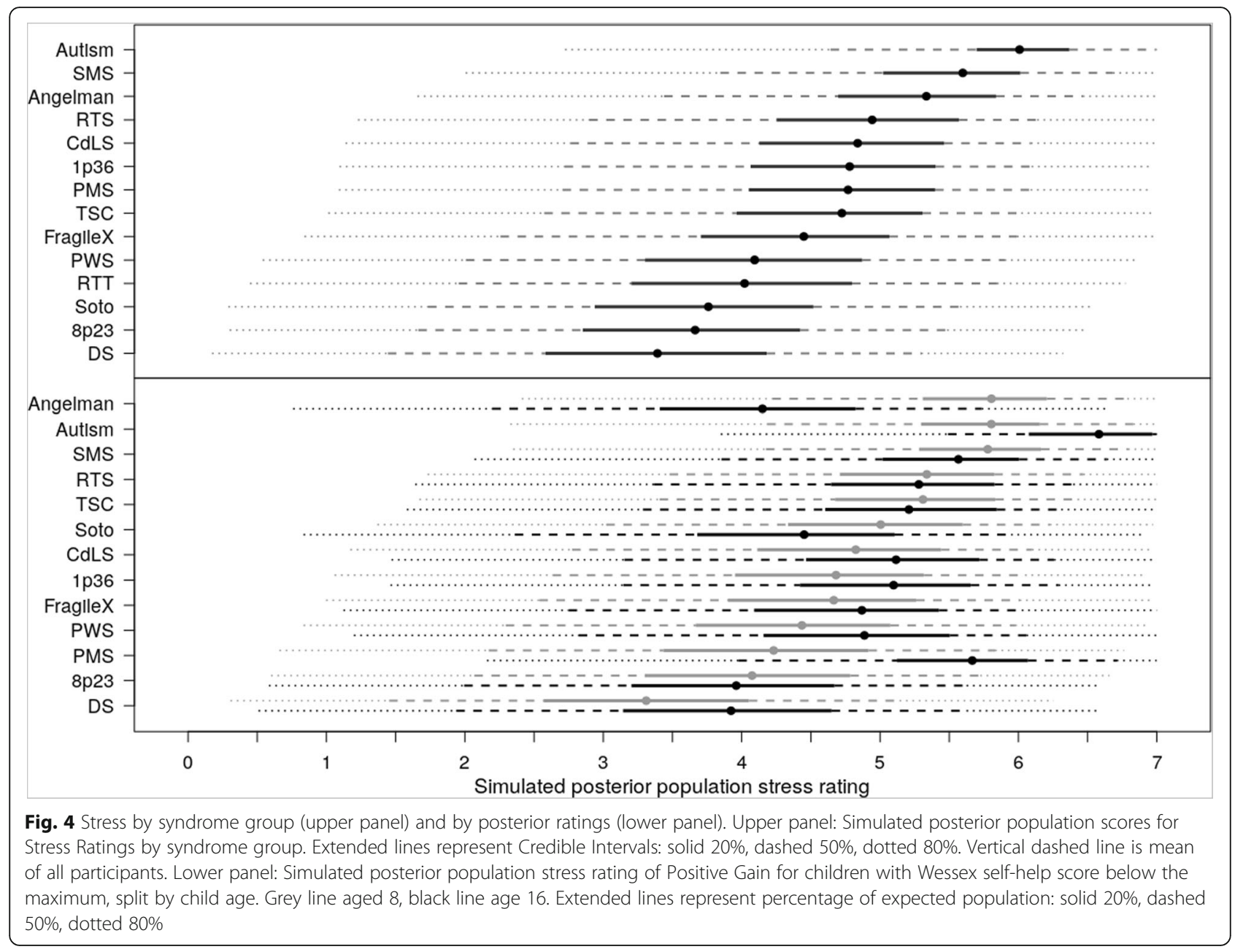

syndromes to tailor services and provide proactive services within syndrome-specific at-risk areas [32, 65]. The results of this study highlight potential factors in being able to begin to identify mothers of children with specific syndromes who may be particularly vulnerable to mental health problems, and raise the possibility of targeted and early support for families. Given that parental stress is associated with child progress and response to intervention [66], it is important for both clinicians and researchers within this field to be aware of parents who may be at increased risk of stress or mental health problems, and who as a result, may find it difficult to benefit from standard parenting interventions. As noted [67], the best approach may be to integrate stress or depression reduction techniques into the early stages of parent training packages for high-risk parents to maximise the effectiveness of the standard training intervention. Studies such as this may also assist with directing parents to syndrome-informed early support and helpful resources to develop effective support networks.
Our identification of specific factors that influence positive maternal health is novel. Positive mental health is not the opposite of mental health difficulties, and this is highlighted in the patterns within syndromes. For example, although the AS mothers are amongst the most stressed of the syndromes assessed, they are reportedly relatively high positive affect. Interestingly, unlike the data for stress and depression, level of ability (as measured by the Wessex) did not influence positive mental health but instead, syndrome, child and parent age were important. Although research on parental positivity in the field of IDD is still in its infancy, the present research suggests that there may be some within (genetic) disability group variation that should be further explored in relation to parent and child demographic variables.

There are several limitations to the present study. Firstly, there is a possible ascertainment bias, as parents were recruited through syndrome support groups. The method of recruitment did not allow for any details on non-responders, who may have potentially been experiencing more difficulties which prevented 
Table 3 Posterior estimates of mean (+ 90\% credible interval) for continuous measure (median for stress) of maternal mental health with posterior probability of differing from autism

\begin{tabular}{|c|c|c|c|c|c|c|c|c|c|}
\hline \multirow[t]{2}{*}{ Syndrome } & \multicolumn{2}{|l|}{ Positive Gain } & \multicolumn{2}{|l|}{ Positive Affect } & \multicolumn{3}{|l|}{ Depression } & \multicolumn{2}{|l|}{ Stress } \\
\hline & $\begin{array}{l}\text { Mean } \\
(90 \% \text { Crl) }\end{array}$ & $\begin{array}{l}\text { Posterior prob. } \\
\text { of difference } \\
\text { with ASD }\end{array}$ & $\begin{array}{l}\text { Mean } \\
(90 \% \text { Crl) }\end{array}$ & Inclusion prob. & $\begin{array}{l}\text { Mean } \\
(90 \% \text { Crl) }\end{array}$ & $\begin{array}{l}\text { Posterior prob. } \\
\text { of difference } \\
\text { with ASD. }\end{array}$ & $\begin{array}{l}\text { Posterior prob. } \\
\text { of being clinically } \\
\text { depressed }\end{array}$ & $\begin{array}{l}\text { Median } \\
(90 \% \text { Crl) }\end{array}$ & $\begin{array}{l}\text { Posterior prob. } \\
\text { of difference } \\
\text { with ASD }\end{array}$ \\
\hline$\overline{A S D}$ & $\begin{array}{l}21.66 \\
(20.99-22.33)\end{array}$ & - & $\begin{array}{l}15.25 \\
(14.83-15.67)\end{array}$ & - & $\begin{array}{l}7.12 \\
(6.63-7.62)\end{array}$ & - & .51 & $6(6-6)$ & - \\
\hline AS & $\begin{array}{l}21.55 \\
(20.20-22.89)\end{array}$ & .56 & $\begin{array}{l}16.60 \\
(16.37-17.65)\end{array}$ & .94 & $\begin{array}{l}6.03 \\
(4.88-7.18)\end{array}$ & .93 & .41 & $5(5-6)$ & .95 \\
\hline CdLS & $\begin{array}{l}21.66 \\
(20.57-22.81)\end{array}$ & .49 & $\begin{array}{l}15.51 \\
(15.36-16.35)\end{array}$ & .64 & $\begin{array}{l}6.92 \\
(6.00-7.90)\end{array}$ & .67 & .49 & $5(4-6)$ & 1 \\
\hline DS & $\begin{array}{l}22.42 \\
(20.91-23.86)\end{array}$ & .80 & $\begin{array}{l}15.93 \\
(15.70-17.07)\end{array}$ & .76 & $\begin{array}{l}4.79 \\
(3.65-5.88)\end{array}$ & 1.00 & .29 & $3(2-5)$ & 1 \\
\hline FXS & $\begin{array}{l}21.66 \\
(20.27-22.42)\end{array}$ & .51 & $\begin{array}{l}15.77 \\
(15.67-16.34)\end{array}$ & .83 & $\begin{array}{l}5.61 \\
(4.94-6.26)\end{array}$ & 1.00 & .37 & $4(4-5)$ & 1 \\
\hline PMS & $\begin{array}{l}22.98 \\
(21.65-24.34)\end{array}$ & .94 & $\begin{array}{l}16.03 \\
(15.83-17.06)\end{array}$ & .83 & $\begin{array}{l}6.13 \\
(4.99-7.30)\end{array}$ & .90 & .41 & $5(4-6)$ & 1 \\
\hline PWS & $\begin{array}{l}21.06 \\
(20.27-21.84)\end{array}$ & .84 & $\begin{array}{l}15.65 \\
(15.54-16.23)\end{array}$ & .77 & $\begin{array}{l}6.12 \\
(5.47-6.79)\end{array}$ & .97 & .41 & $4(4-5)$ & 1 \\
\hline RTT & $\begin{array}{l}22.71 \\
(21.90-23.54)\end{array}$ & .95 & $\begin{array}{l}17.23 \\
(17.10-17.86)\end{array}$ & 1 & $\begin{array}{l}4.70 \\
(4.01-5.38)\end{array}$ & 1.00 & .29 & $4(3-5)$ & 1 \\
\hline RTS & $\begin{array}{l}22.70 \\
(21.58-23.83)\end{array}$ & .91 & $\begin{array}{l}15.07 \\
(14.90-15.91)\end{array}$ & .60 & $\begin{array}{l}5.36 \\
(4.43-6.29)\end{array}$ & 1.00 & .34 & $5(4-6)$ & 1 \\
\hline SMS & $\begin{array}{l}21.70 \\
(20.13-23.33)\end{array}$ & .52 & $\begin{array}{l}15.62 \\
(15.35-16.79)\end{array}$ & .64 & $\begin{array}{l}7.66 \\
(6.28-9.02)\end{array}$ & .74 & .56 & $6(5-6)$ & .83 \\
\hline Soto & $\begin{array}{l}21.78 \\
(20.51-22.96)\end{array}$ & .57 & $\begin{array}{l}15.53 \\
(15.32-16.49)\end{array}$ & .63 & $\begin{array}{l}5.42 \\
(4.39-6.43)\end{array}$ & .99 & .35 & $4(3-5)$ & 1 \\
\hline TSC & $\begin{array}{l}21.64 \\
(20.76-22.53)\end{array}$ & .50 & $\begin{array}{l}15.32 \\
(15.17-16.01)\end{array}$ & .54 & $\begin{array}{l}5.88 \\
(5.14-6.63)\end{array}$ & .99 & .39 & $5(4-5)$ & 1 \\
\hline $1 p 36$ & $\begin{array}{l}21.64 \\
(20.28-23.05)\end{array}$ & .51 & $\begin{array}{l}15.63 \\
(15.42-16.68)\end{array}$ & .66 & $\begin{array}{l}6.96 \\
(5.84-8.15)\end{array}$ & .57 & .50 & $5(4-6)$ & .99 \\
\hline $8 p 23$ & $\begin{array}{l}21.89 \\
(20.35-23.38)\end{array}$ & .60 & $\begin{array}{l}16.86 \\
(16.64-17.96)\end{array}$ & .96 & $\begin{array}{l}4.82 \\
(3.54-6.13)\end{array}$ & 1.00 & .30 & $4(2-5)$ & 1 \\
\hline
\end{tabular}

Posterior probability of difference $=1$ indicates posterior distributions of estimate highly unlikely to be equivalent. Posterior probability $=0$ indicates no detectable difference

them from completing the questionnaire. There is also no assessment of socioeconomic status. However, these potential biases are likely to have applied across the genetic syndrome groups, and may have had limited impact on the cross-sectional comparison. Another limitation is that confirmation of genetic testing was not checked for each participant. Detailed genetic information on each participant would allow for further exploration of maternal mental health and well-being in relation to genetic subtypes and other factors such as hereditability. Whilst all parents were members of specific support groups, it was only possible to provide some level of validation within the ASD group (by only including participants who score above the cut-off on the SCQ, albeit not a diagnostic criterion).

Secondly, the study is cross-sectional and has a large sample with a large age range and so does not allow for comment on the course or progression of the maternal outcomes explored. The range of factors explored was also limited and as discussed above, further studies are needed to explore the relative impact of both behavioural and non-behavioural factors on parental well-being. Longitudinal studies of parents of children with idiopathic intellectual disability and those with autism suggest that parental stress may reduce as children age, but this is largely dependent upon help received and the presence or severity of challenging behaviour [68]. Longitudinal methodologies would allow exploration over time of the stability and course of the mental health of mothers of children with rare genetic syndromes and neurodevelopmental disorders [69] and are increasingly important given the suggestion of change in some behavioural phenotypes with age (e.g. [70]). Whilst it is arguably the only way in which to collect a sample of this size and breadth, the limitations of collecting information via informant 
questionnaires should be recognised, especially in relation to providing in-depth sample characterisation.

\section{Conclusions}

In conclusion, this study uses Bayesian statistical modelling in a novel manner to highlight the level of variability in mental health amongst mothers of children with rare genetic disorders and neurodevelopmental disorders. To date, mothers of children with autism have been shown to be a high-risk group, experiencing the highest levels of stress and mental health problems of parents with children with neurodevelopmental disorders [71]. Such a perspective should now be broadened, as the data here show that there are notable proportions of mothers of children with specific genetic syndromes who experience levels of depression and stress similar to the levels reported by mothers of children with autism. Further research is needed to explore the broader parent and child characteristics, including behavioural and family characteristics that are contributing to such elevated mental health difficulties.

\section{Key points}

- Little is known about the mental health of mothers of children with rare genetic syndromes

- Different aspects of maternal mental health are influenced by different child and mother factors

- Depression levels are comparable between mothers of children with Smith Magenis, 1p36 and Cornelia de Lange syndromes and autism

- Stress levels are comparable between mothers of children with Smith Magenis, Angelman syndromes and autism

- Further work is needed to explore the relationship between maternal mental health, syndromes and other child and mother variables.

\section{Additional file}

Additional file 1: Classification and regression tree (CART) diagrams for each measure. (PDF $58 \mathrm{~kb}$ )

\section{Abbreviations}

1p36: 1 p36 deletion syndrome; 8p23: 8p23 deletion syndrome; AS: Angelman syndrome; ASD: Autism Spectrum Disorder; CdLS: Cornelia de Lange syndrome; DS: Down syndrome; FXS: Fragile-X syndrome; PMS: Phelan McDermid syndrome; PWS: Prader-Willi syndrome; RTS: Rubenstein Taybi syndrome; RTT: Rett syndrome; SMS: Smith Magenis syndrome;

TSC: Tuberous Sclerosis Complex

\section{Acknowledgements}

We are grateful to all the parents and families for taking part in this research and for the syndrome support groups for facilitating the data collection. This paper presents independent research partly funded by the National Institute for Health Research (NIHR) Post-Doctoral Fellowship Programme (grant number
PDF-2010-03-02), Cerebra, Jerome Lejeune, Baily Thomas Charitable Funds and the National Institute for Social Care and Health Research (NISCHR) Social Care Studentship Scheme (grant number SCS/08-01). The views expressed are those of the author(s) and not necessarily those of the NHS, the NIHR, the NISCHR, Cerebra or the Department of Health.

\section{Funding}

This paper presents independent research partly funded by the National Institute for Health Research (NIHR) Post-Doctoral Fellowship Programme (grant number PDF-2010-03-02), Cerebra, Jerome Lejeune, Baily Thomas Charitable Funds and the National Institute for Social Care and Health Research (NISCHR) Social Care Studentship Scheme (grant number SCS/08-01). None of these funders were involved in the design, recruitment, analysis or data interpretation of this individual study but provided ongoing core funding for research at the Cerebra Centre for Neurodevelopmental Disorders.

\section{Authors' contributions}

DA co-designed the study, carried out the analyses, drafted the initial manuscript, reviewed and revised the manuscript and finalized the manuscript for submission. RH co-designed the study, supervised the analyses, critically reviewed the manuscript, and approved the final manuscript as submitted. CA-K provided the statistical input for the study and approved the final manuscript as submitted. $\mathrm{RC}$ undertook the data collection and data entry at the Rett syndrome study site, critically reviewed the manuscript, and approved the final manuscript as submitted. KE coordinated and supervised the data collection and collated datasets for analyses from 2011 to 12, critically reviewed the manuscript, and approved the final manuscript as submitted. GG derived a number of the measures used in this study, critically reviewed the manuscript, and approved the final manuscript as submitted. DF supervised the data collection and data entry at the Rett syndrome study site, critically reviewed the manuscript, and approved the final manuscript as submitted. JM has coordinated and supervised the data collection and data entry at the main study site since the start of data collection in 2006, critically reviewed the manuscript, and approved the final manuscript as submitted. CS coordinated and supervised the data collection and collated datasets for analyses from 2009 to 2011, critically reviewed the manuscript, and approved the final manuscript as submitted. CO conceptualized and co-designed the study, critically reviewed the manuscript, and approved the final manuscript as submitted. All authors read and approved the final manuscript.

\section{Ethics approval and consent to participate}

Ethical approval was obtained for this study in 2010 from Coventry Research Ethics Committee, as part of a larger ongoing study entitled 'Understanding behaviour and family adjustment in individuals with neurodevelopmental disorders'. REC reference number: 10/H1210/01. All patients gave informed consent for the research use and anonymised publication of their data in accordance with the Declaration of Helsinki. Ethical approval was received from both the HREC and University boards.

\section{Consent for publication}

Not applicable.

\section{Competing interests}

The authors declare that they have no competing interests.

\section{Publisher's Note}

Springer Nature remains neutral with regard to jurisdictional claims in published maps and institutional affiliations.

\footnotetext{
Author details

${ }^{1}$ Cerebra Centre for Neurodevelopmental Disorders, School of Psychology, University of Birmingham, Birmingham B15 2TT, UK. ${ }^{2}$ Autism Centre of Excellence, School of Education and Professional Studies, Griffith University, Brisbane, Australia. ${ }^{3}$ Centre for Educational Development Appraisal and Research, University of Warwick, Warwick, UK. ${ }^{4}$ Griffith Social and Behavioural Research College, Griffith University, Brisbane, Australia. ${ }^{5}$ Welsh Centre for Learning Disabilities, Cardiff University, Cardiff, UK. ${ }^{6}$ School of Psychology, Bangor University, Bangor, UK.
} 
Received: 17 April 2018 Accepted: 2 October 2018

Published online: 25 October 2018

\section{References}

1. Emerson E, Hatton C, Llewellyn G, Blacker J, Graham H. Socio-economic position, household composition, health status and indicators of the well-being of mothers of children with and without intellectual disabilities. J Intellect Disabil Res. 2006;50:862-73. https://doi.org/10.1111/J.1365-2788.2006.00900.X.

2. Gallagher S, Hannigan A. Depression and chronic health conditions in parents of children with and without developmental disabilities: the growing up in Ireland cohort study. Res Dev Disabil. 2014;35(2):448-54. https://doi.org/10.1016/J.Ridd.2013.11.029.

3. Totsika V, Hastings RP, Emerson E, Lancaster GA, Berridge DM. A populationbased investigation of behavioural and emotional problems and maternal mental health: associations with autism spectrum disorder and intellectual disability. J Child Psychol Psychiatry. 2011;52(1):91-9. https://doi.org/10.1111/ J.1469-7610.2010.02295.X.

4. Baker BL, Blacher J, Crnic KA, Edelbrock C. Behavior problems and parenting stress in families of three-year-old children with and without developmental delays. Am J Ment Retard. 2002;107(6):433-44. https://doi.org/10.1352/08958017(2002)107<0433:Bpapsi>2.0.Co;2.

5. Adams D, Clarke S, Griffith G, Howlin P, Moss J, Petty J, et al. Mental health and wellbeing in mothers of children with genetic syndromes showing chronic challenging behavior: a cross-sectional and longitudinal study. Am J Intellect Dev Disabil. 2018;123(3):241-53.

6. Montes $G$, Halterman JS. Psychological functioning and coping among mothers of children with autism: a population-based study. Pediatrics. 2007; 119(5):E1040-6. https://doi.org/10.1542/Peds.2006-2819.

7. Hayes SA, Watson SL. The impact of parenting stress: a meta-analysis of studies comparing the experience of parenting stress in parents of children with and without autism spectrum disorder. J Autism Dev Disord. 2013;43: 629-42. https://doi.org/10.1007/s10803-012-1604-y.

8. Paynter J, Davies M, Beamish W. Recognising the "forgotten man": fathers' experiences in caring for a young child with autism spectrum disorder. J Intellect Develop Disabil. 2018;43(1):112-24. https://doi.org/10.3109/ 13668250.2017.1293235.

9. Oliver C, Woodcock K. Integrating levels of explanation in behavioural phenotype research. J Intellect Disabil Res. 2008;52:807-9. https://doi.org/10. 1111/j.1365-2788.2008.01117.x.

10. Vissers LE, Gilissen C, Veltman J. Genetic studies in intellectual disability and related disorders. Nat Rev Genet. 2016;17:9-18. https://doi.org/10. 1038/nrg3999

11. Abbeduto $L$, Boudreau D. Theoretical influences on research on language development and intervention in individuals with mental retardation. Ment Retard Dev Disabil Res Rev. 2004;10(3):184-92. https://doi.org/10.1002/Mrdd. 20032.

12. Eisenhower AS, Baker BL, Blacher J. Preschool children with intellectual disability: syndrome specificity, behaviour problems, and maternal wellbeing. J Intellect Disabil Res. 2005;49:657-71. https://doi.org/10.1111/J.13652788.2005.00699.X

13. Bourke J, Ricciardo B, Bebbington A, Alberti K, Jacoby P, Dyke P, et al. Physical and mental health in mothers of children with Down syndrome. J Pediatr. 2008;153(3):320-6. https://doi.org/10.1016/J.Jpeds.2008.02.047.

14. Glidden LM, Grein KA, Ludwig JA. The Down syndrome advantage: it depends on what and when you measure. Am J Intellect Dev Disabil. 2014; 119(5):389-404. https://doi.org/10.1352/1944-7558-119.5.389.

15. Fidler DJ, Hodapp RM, Dykens EM. Behavioral phenotypes and special education: parent report of educational issues for children with Down syndrome, Prader-Willi syndrome, and Williams syndrome. J Spec Educ. 2002;36(2):80-8. https://doi.org/10.1177/00224669020360020301.

16. Richman DM, Belmont JM, Kim M, Slavin CB, Hayner AK. Parenting stress in families of children with Cornelia de Lange syndrome and Down syndrome. J Dev Phys Disabil. 2009;21(6):537-53. https://doi.org/10.1007/S10882-009-9156-6.

17. Griffith GM, Hastings RP, Oliver C, Howlin P, Moss J, Petty J, et al. Psychological well-being in parents of children with Angelman, Cornelia de Lange and cri du chat syndromes. J Intellect Disabil Res. 2011:55:397-410. https://doi.org/10.1111/J.1365-2788.2011.01386.X

18. Hodapp RM. Direct and indirect behavioral effects of different genetic disorders of mental retardation. Am J Ment Retard. 1997;102(1):67-79. https://doi.org/10.1352/0895-8017(1997)102<0067:Daibeo>2.0.Co;2.
19. Blacher J, Baker BL, Kaladjian A. Syndrome specificity and mother-child interactions: examining positive and negative parenting across contexts and time. J Autism Dev Disord. 2013;43(4):761-74 https://doi.org/10.1007/ s10803-012-1605-X.

20. Bonis S. Stress and parents of children with autism: a review of literature. Issues Ment Health Nurs. 2016;37(3):153-63. https://doi.org/10.3109/ 01612840.2015 .1116030

21. Yorke I, White P, Weston A, et al. The association between emotional and behavioral problems in children with autism spectrum disorder and psychological distress in their parents: a systematic review and metaanalysis. J Autism Dev Disord. 2018;48(10):3393-415. https://doi.org/10.1007/ s10803-018-3605-y.

22. Corcoran J, Berry A, Hill S. The lived experience of US parents of children with autism spectrum disorders: a systematic review and meta-synthesis. J Intellect Disabil. 2015;19(4):356-66 https://doi.org/10.1177/ 1744629515577876

23. Lai WW, Oei TPS. Coping in parents and caregivers of children with autism spectrum disorders (ASD): a review. Rev J Autism Dev Disord. 2014;1(3):20724 https://doi.org/10.1007/s40489-014-0021-x.

24. Hastings RP, Taunt HM. Positive perceptions in families of children with developmental disabilities. Am J Ment Retard. 2002;107(2):116-27. https:// doi.org/10.1352/0895-8017(2002)107<0116:Ppifoc>2.0.Co;2.

25. Horsley S, Oliver C. Positive impact and its relationship to well-being in parents of children with intellectual disability: a literature review. Int I Dev Disabil. 2015;61(1):1-19. https://doi.org/10.1179/2047387713y.0000000026.

26. Griffith G. Psychological stress in mothers of children with genetic syndromes. Wales: Bangor University; 2011.

27. Moss J, Oliver C, Arron K, Burbridge C, Berg K. The prevalence and phenomenology of repetitive behaviour in genetic syndromes. Journal of Autism and Developmental Disorders. 2009;39:572-88. https://doi.org/10. 1007/s10803-008-0655-6.

28. Cianfaglione R, Clarke A, Kerr M, Hastings RP, Oliver C, Moss J, et al. A national survey of Rett syndrome: behavioural characteristics. Journal of Neurodevelopmental Disorders. 2015;7(1):11. https://doi.org/10.1186/s11689015-9104-y.

29. Rutter M, Bailey A, Lord C. Social Communication Questionnaire. Los Angeles: Western psychological services; 2003.

30. Clayton-Smith J, Laan L. Angelman syndrome: a review of the clinical and genetic aspects. J Med Genet. 2003;40(2):87-95. https://doi.org/10.1136/jmg. 40.2.87.

31. Coffee B, Keith K, Albizua I, Malone T, Mowrey J, Sherman SL, et al. Incidence of fragile $X$ syndrome by newborn screening for methylated FMR1 DNA. Am J Hum Genet. 2009;85(4):503-14. https://doi.org/10.1016/j.ajhg.2009.09.007.

32. Redley M, Pannebakker M, Holland A. Improving the health and wellbeing of adults with conditions of a genetic origin: views from professionals, syndrome support groups and parents. J Appl Res Intellect Disabil. 2018:31:62-75.

33. Kushlick A, Blunden R, Cox G. Method of rating behavior characteristics for use in 558 large-scale surveys of mental handicap. Psychol Med. 1973;3:466-78.

34. Richards C, Moss J, Nelson L, Oliver C. Persistence of self-injurious behaviour in autism spectrum disorder over 3 years: a prospective cohort study of risk markers. J Neurodev Disord. 2016:8:21. https://doi.org/10.1186/s11689-016-9153-x.

35. Waite J, Moss J, Beck SR, Richards C, Nelson L, Arron K, et al. Repetitive behavior in Rubinstein-Taybi syndrome: parallels with autism spectrum phenomenology. J Autism Dev Disord. 2015;45(5):1238-53. https://doi.org/ 10.1007/s10803-014-2283-7.

36. Pit-ten Cate I. Positive gain in mothers of children with physical disabilities. Unpublished PhD thesis, University of Southampton, United Kingdom: 2003.

37. Watson D, Clark LA, Tellegan A. Development and validation of brief measures of positive and negative affect: the PANAS scales. J Pers Soc Psychol. 1988;54(6):1063-70.

38. Zigmond AS, Snaith RP. The hospital anxiety and depression scale. Acta Psychiatr Scand. 1983;67(6):9.

39. Bjelland I, Dahl AA, Haug TT, Neckelmann D. The validity of the Hospital Anxiety and Depression Scale - An updated literature review. J Psychosom Res. 2002;52(2):69-77.

40. Jones L, Hastings RP, Totsika V, Keane L, Rhule N. Child behavior problems and parental well-being in families of children with autism: the mediating role of mindfulness and acceptance. Am J Intellect Dev Disabil. 2014;119(2):171-85. https://doi.org/10.1352/1944-7558-119.2.171. 
41. Friedrich WN, Greenburg MT, Crnic K. A short form of the questionnaire on resources and stress. Am J Ment Defic. 1983;88:41-8.

42. Adams D, Rose J, Jackson N, Karakatsani E, Oliver C. Coping strategies in mothers of children with intellectual disabilities showing multiple forms of challenging behaviour: associations with maternal mental health. Behav Cogn Psychother. 2017. https://doi.org/10.1017/S1352465817000704IF.

43. Dawson F, Shanahan S, Fitzsimons E, O'Malley G, Mac Giollabhui N, Bramham J. The impact of caring for an adult with intellectual disability and psychiatric comorbidity on carer stress and psychological distress. J Intellect Disabil Res. 2016;60:553-63. https://doi.org/10.1111/jir.12269.

44. van de Schoot R, Kaplan D, Denissen J, Asendorpf J, Neyer F, van Aken M. A gentle introduction to Bayesian analysis: applications to developmental research. Child Dev 2014;85:842-860. doi:https://doi.org/10.1111/cdev. 121692013.

45. Gopnik A, Tenenbaum J. Bayesian networks, Bayesian learning and cognitive development. Dev Sci. 2007;10(3):281-7.

46. Oldehinkel AJ. Editorial: Bayesian benefits for child psychology and psychiatry researchers. J Child Psychol Psychiatry. 2016;57(9):985-7. https:// doi.org/10.1111/jcpp.12619.

47. De Finetti B. Theory of probability, vol. 1. New York: Wiley; 1974.

48. Martin AD, Quinn KM, Park JH. MCMCpack: Markov chain Monte Carlo in R. J Stat Softw. 2011;42(9):1-21.

49. R Core Team R. A language and environment for statistical computing. Vienna: R Foundation for Statistical Computing; 2016. https://www.R-project. org/. Accessed 5 Dec 2017

50. Raferty AE. Bayesian model selection in social research. Sociol Methodol. 1995;25:111-63.

51. Clyde M. BAS: Bayesian adaptive sampling for Bayesian model averaging Version R package version 1.4.6. 2017.

52. R Core Team R. A language and environment for statistical computing. Vienna: R Foundation for Statistical Computing; 2017. https://www.R-project.org/. Accessed 5 Dec 2017

53. Cowles MK. Accelerating Monte Carlo Markov chain convergence for cumulative-link generalised linear models. Stat Comput. 1996;6:101-11 doi: https://doi.org/10.1007/BF00162520.

54. Betancur C. Etiological heterogeneity in autism spectrum disorders: more than 100 genetic and genomic disorders and still counting. Brain Res. 2011; 138:42-77. https://doi.org/10.1016/j.brainres.2010.11.078.

55. Laje G, Morse R, Richter W, Ball J, Pao M, Smith AC. Autism spectrum features in smith-Magenis syndrome. Am J Med Genet C Semin Med Genet 2010;154C(4):456-62. doi:https://doi.org/10.1002/ajmg.c.30275.

56. Richards C, Jones C, Groves L, Moss J, Oliver C. Prevalence of autism spectrum disorder phenomenology in genetic disorders: a systematic review and meta-analysis. Lancet Psychiatry. 2015;2(10):909-16. https://doi. org/10.1016/S2215-0366(15)00376-4.

57. Lane C, Milne E, Freeth M. Characteristics of autism spectrum disorder in Sotos syndrome. J Autism Dev Disord. 2017;47(1):135-43. https://doi.org/10. 1007/s10803-016-2941-z.

58. Oberman LM, Boccuto L, Cascio L, Sarasua S, Kaufmann WE. Autism spectrum disorder in Phelan-McDermid syndrome: initial characterization and genotype-phenotype correlations. Orphanet J Rare Dis. 2015;10:105. https://doi.org/10.1186/s13023-015-0323-9.

59. Konstantareas M, Papageorgiou V. Effects of temperament, symptom severity and level of functioning on maternal stress in Greek children and youth with ASD. Autism. 2006;10(6):593-607. https://doi.org/10.1177/ 1362361306068511.

60. Hodapp RM, Dykens EM. Genetic disorders of intellectual disability: expanding our concepts of phenotypes and of family outcomes. J Genet Counsel. 2012;21(6):761-9 https://doi.org/10.1007/s10897-012-9536-4.

61. Pearson EV, Oliver C, Waite J. Differences in the information needs of parents with a child with a genetic syndrome: a cross-syndrome comparison. J Policy Pract Intellect Disabil. 2018;15(2):94-100. https://doi. org/10.1111/jppi.12231.

62. Griffith GM, Hastings RP, Nash S, Petalas M, Oliver C, Howlin P, et al. "you have to sit and explain it all, and explain yourself." Mothers' experiences of support services for their offspring with a rare genetic intellectual disability syndrome. J Genet Couns. 2011;20(2):165-77. https://doi.org/10.1007/ S10897-010-9339-4.

63. Oliver C, Adams D, Allen D, Bull L, Heald M, Moss J, et al. Causal models of clinically significant behaviors in Angelman, Cornelia de Lange, Prader-Willi and Smith-Magenis syndromes. Int Rev Res Dev Disabil. 2013;44:167-211.
64. Cochran L, Moss J, Nelson L, Oliver C. Contrasting age related changes in autism spectrum disorder phenomenology in Cornelia de Lange, fragile $X_{\text {, }}$ and cri du chat syndromes: results from a 2.5 year follow-up. Am J Med Genet C Semin Med Genet 2015;169(2):188-97. doi:https://doi.org/10.1002/ ajmg.c.31438.

65. Kalsy S, McQuillan S, Adams D, Basra T, Konstantinidi E, Broquard M, et al. A proactive psychological strategy for determining the presence of dementia in adults with Down syndrome: preliminary description of service use and evaluation. J Pol and Pract Intellect Disabil. 2005;2(2):116-25 https://doi.org/ 10.1111/j.1741-1130.2005.00025.x.

66. Robbins FR, Dunlap G, Plienis AJ. Family characteristics, family training, and the progress of young children with autism. J Early Interv. 1991;15(2):173-84.

67. Crnic KA, Neece CL, McIntyre LL, Blacher J, Baker BL. Intellectual disability and developmental risk: promoting intervention to improve child and family well-being. Child Dev. 2017:88(2):436-45. https://doi.org/10.1111/ cdev. 12740

68. Baxter C, Cummins RA, Yiolitis L. Parental stress attributed to family members with and without disability: a longitudinal study. J Intellect Develop Disabil. 2000;25(2):105-18.

69. Cianfaglione R, Hastings RP, Felce D, Clarke A, Kerr MP. Change over a 16month period in the psychological well-being of mothers of girls and women with Rett syndrome. Dev Neurorehabil. 2017;20(5):261-5. https://doi. org/10.3109/17518423.2016.1142483.

70. Adams D, Horsler K, Mount R, Oliver C. Brief report: a longitudinal study of excessive smiling and laughing in children with Angelman syndrome. J Autism Dev Disord. 2015;45(8):2624-7.

71. Totsika V, Hastings RP, Emerson E, Berridge DM, Lancaster GA. Behavior problems at 5 years of age and maternal mental health in autism and intellectual disability. J Abnorm Child Psychol. 2011;39(8):1137-47. https:// doi.org/10.1007/S10802-011-9534-2.

\section{Ready to submit your research? Choose BMC and benefit from:}

- fast, convenient online submission

- thorough peer review by experienced researchers in your field

- rapid publication on acceptance

- support for research data, including large and complex data types

- gold Open Access which fosters wider collaboration and increased citations

- maximum visibility for your research: over $100 \mathrm{M}$ website views per year

At BMC, research is always in progress.

Learn more biomedcentral.com/submissions 